\title{
Does climate warming influence sexual chemical signaling?
}

\author{
Astrid T. Groot ${ }^{1}$ and Z. Valentina Zizzari ${ }^{2, *}$ \\ ${ }^{1}$ IBED, University of Amsterdam, Science Park 904, 1098 XH, Amsterdam, The Netherlands \\ ${ }^{2}$ Institute for Integrated Natural Sciences, Department of Biology - division Zoology, University of \\ Koblenz-Landau, Universitätsstraße 1, 56070 Koblenz, Germany
}

Submitted: September 29, 2018. Final revision received: January 11, 2019.

Accepted: January 28, 2019

\begin{abstract}
Global climate is changing at a rapid pace and the pivotal question is if the rate and extent of species' responses to stressful events enable them to persist in a changing world. Although the consequences of rapid environmental changes on animal life-history traits are receiving considerable attention, our understanding of how temperature fluctuations affect sexual chemical communication in animals is scarce. Male-female interactions often depend on pheromone detectability and sudden shifts in environmental temperature are expected to disrupt communication between potential mates. Whether organisms can adapt to temperature-induced changes at both signaller and receiver levels is virtually unexplored. In this perspective paper, we first provide a broad overview of the sex pheromone pathway, from biosynthesis to detection, and outline the importance of chemical-based mate choice. Finally, through several study cases, we highlight how thermal stress may interfere with chemical communication between the sexes, and discuss the potential evolutionary consequence of temperature stress.
\end{abstract}

\section{Keywords}

Chemical communication; climate change; mating disruption; sex pheromone; thermal stress

\section{Introduction}

The ability to effectively communicate with other individuals shapes the life of all animals. However, animal communication can be compromised by anthropogenic influences (see e.g., Lürling \& Scheffer, 2007; Rosenthal \& Stuart-Fox, 2012).

A primary means of contact between individuals in many animal species is represented by odour (Wyatt, 2014). Studies of the effects of global change on

*) Corresponding author; e-mail: zvzizzari@uni-koblenz.de 
pheromones suggest that these molecules might be impaired by variations in environmental parameters, with important consequences for the ecosystem (see e.g., Boullis et al., 2016; Henneken \& Jones, 2017). For instance, high temperature can accelerate pheromone decay, thus affecting communication between individuals and the resulting behavioural response (e.g., foraging behaviour in ants: van Oudenhove et al., 2011). Functions such as feeding and communication can be compromised also by an impaired ability of smelling or detecting odours. Several studies indicate a sensitivity of animal olfactory systems to several stressors: elevated $\mathrm{CO}_{2}$ decreases the ability to detect food or predators in the European sea bass, Dicentrarchus labrax (Linnaeus, 1758) (Porteus et al., 2018) and high temperatures have been shown to hamper the odour-discriminating ability of the Chinese pond turtle, Geoclemys reevesii (Gray, 1831) (Hanada et al., 1994).

Despite the large amount of research on chemical signalling, few studies have tested the consequences of abiotic stress on intersexual signal transmission and detection, particularly of temperature variations. Indeed, chemical signalling plays a crucial role at different levels of sexual communication, not only allowing mate identification (i.e., species recognition), but also mediating mate assessment (see e.g., Harari et al., 2011; Thomas, 2011; Chemnitz et al., 2015). Thus, an impairment of efficacy of chemically mediated sexual signals due to climate change is expected to have profound impact on animal reproductive success with important consequences for sexual selection. Individuals might not be able to recognise or assess potential mates and thus become less choosy. In this scenario, same-sex competition may become more relaxed. Given that mate choice has been suggested to exert selection on chemical traits (Steiger \& Stökl, 2014; Wyatt, 2014), changes in signal transmission and detection might lead to disruption of sexual selection.

In this perspective paper, we focus on possible effects of extreme temperature events on pheromones that are used in intersexual relationships. We first provide a broad overview of the journey of sex pheromones and highlight their importance for animal sexual behaviour. We then illustrate examples across several taxa where thermal stress affects the efficacy of transmission and/or detection of sex pheromones. Our aim is to prompt further consideration of a research area that has received limited attention so far.

\section{Sex pheromones: chemical nature and biosynthesis}

A sex pheromone is a molecule or a blend of molecules used specifically for intersexual communication. When a pheromone has a behavioural effect on the receiver, it is usually called a "releaser pheromone"; when it causes a physiological change in the receiver by stimulating hormone secretion, it is referred to as a "primer pheromone" (Wyatt, 2014). Many pheromones induce both releaser effects and long-term primer effects (Wyatt, 2017). Here we do not emphasize the differences between releaser and primer pheromones and refer to both types as "pheromones". The chemical nature of animal sex pheromones is highly diverse. 
Sex pheromones can consist of saturated or unsaturated hydrocarbon chains with a functional group. They can be short(er) carbon chain volatiles that attract potential mating partners from a longer or shorter distance, or long(er) carbon chain cuticular hydrocarbons (CHCs) that are used to identify potential mating partners upon contact. The volatility in air and solubility in water is determined by their size and polarity. The chemical nature and production pathways of sex pheromones vary tremendously across taxa. Sex pheromones can be produced de novo in specialized glands or tissues. For instance, most male lizards have femoral glands secreting both lipophilic and proteinaceous compounds, while the sex peptide pheromones of female newts are secreted by abdominal glands (see e.g., Martín \& López, 2010; Nakada et al., 2017). Odour communication seems to play an important role for reproduction also in birds, with uropygial glands producing oily secretions likely used for sex recognition in most bird species (Caro et al., 2015).

Sex pheromones may also be derived from other sources. For instance, some insects sequester host plant compounds and use them as sex pheromones or sex pheromone precursors (Landolt \& Phillips, 1997). In some cases, microbes or symbionts participate in pheromone biosynthesis. In moths, pheromone production may depend on sucrose nutrition (Foster \& Johnson, 2010) and temperature (Raina, 2003). In lizards, a relation between diet and sexual chemical communication has been suggested as most of the steroids secreted are of vegetal or microbial origin (Martín \& López, 2014). Urinary odorants are also widely used in sexual chemical communication, such as the sex pheromones of fishes and rodents (see e.g., Brennan \& Zufall, 2006; Keller-Costa et al., 2014).

\section{Pheromone perception/signal detectability}

The complex neural and physiological patterns underlying odour communication do not fall within the scope of this paper; however, it is worth mentioning that odorantbinding proteins of both invertebrates and vertebrates show similarities (Pelosi \& Maida, 1990), with a glomerular organization at the basis of odour processing (Ache \& Young, 2005).

In particular, the most studied mechanisms of pheromonal communication are those of insects, which detect volatile pheromones mostly with their antennae. The antennae harbour sensory sensilla, many of which are dedicated to pheromone reception. These sensilla transform the chemical message into an electrical message transmitted to the brain (Kaissling, 2014). The pheromone molecules enter the sensitive sensilla via cuticular pores and reach the pheromone receptors (PRs) in the dendritic membrane of the olfactory receptor neurons (ORNs) through pheromonebinding proteins (PBPs) (Vogt, 2005). After interaction of the pheromone with its receptor, signal termination may be ensured by pheromone-degrading enzymes in the sensillum lymph. 
Non-volatile close-range pheromones are detected by contact chemodetection that involves taste structures such as the labellum or forelegs, with gustatory receptors (GRs), which are structurally related to olfactory receptors, and/or two transmembrane domain Pickpocket (PKK) ion channels that ensure signal recognition.

In most mammals, reptiles and amphibians, volatile pheromones are detected by the main olfactory epithelium (MOE), consisting of ciliated olfactory sensory neurons, while protein pheromones are detected by the vomeronasal organ (VNO), a blind-ended tube in the nasal septum (Brennan \& Zufall, 2006; Woodley, 2010). Fishes are equipped with ciliated sensory cells only (Hansen et al., 2004). Knowledge of the mechanism of olfactory communication in birds is still scant (Caro \& Balthazart, 2010) but the organization of their olfactory bulbs seems more similar to that in reptiles than that in mammals (Caspermeyer, 2016).

\section{Sex pheromones and mate choice}

Pheromones shape the life of most species in the animal kingdom and are especially important for their sexual behaviour. Pheromones released to attract conspecifics of the opposite sex can convey information about mate age, mating status, nutritional state and genetic compatibility (see e.g., Johansson \& Jones, 2007; Gomez-Diaz \& Benton, 2013). Olfactory-mediated mate choice is shown in both invertebrates and vertebrates. Virgin males of the nematode Caenorhabditis remanei (Sudhaus, 1974) are more attracted to virgin than mated females (Borne et al., 2017). In the cockroach Nauphoeta cinerea (Olivier, 1789), the male sex pheromone varies depending on the carbohydrate intake, and a higher intake increases male attractiveness (South et al., 2011), adding evidence that pheromones can be costly to produce (Steiger et al., 2012). Similarly, one constituent of the male femoral secretions in lizards is represented by oleic acid, which is diverted from the lizard fat reserves. Allocation of this fatty acid to the secretions reflects male body size (Martín \& López, 2010). Given that females prefer the scent of males with high proportions of fatty acids, the concentration of lipid components secreted is likely an honest signal of the actual male condition (Martín \& López, 2010).

If individuals can gain benefits by choosing a partner with a particular sex pheromone profile, sexual selection likely promotes intrasexual differences in sex pheromone blend (i.e., amount and ratio of components). In the rock lizard Iberolacerta monticola (Boulenger, 1905) and in the burying beetle Nicrophorus vespilloides (Herbst, 1783), male quality depends on the relative composition of the pheromone components emitted (Martín et al., 2007; Chemnitz et al., 2015), while in the wasp Nasonia vitripennis (Walker, 1836), sperm load is reflected by the quantity of the male sex pheromone (Ruther et al., 2009). Sex pheromones can have multiple effects, as shown in the house mouse, whose puberty-accelerating pheromone also elicits aggression in males (Novotny, 2003), and in male tilapia, in which the sex pheromone attracts females and primes their ovulation (Keller-Costa 
et al., 2014). Pheromones can also change plastically depending on chemical environment. For example, in the moth Heliothis subflexa (Guenée, 1852), females vary their sex pheromone blend based on the olfactory environment experienced in their early-adult life (Groot et al., 2010). Pheromone expression can be affected also by intra-sexual competition. In the collembolan Orchesella cincta (Linnaeus, 1758), males have been shown to influence female choice by plastically tailoring the expression of the sex pheromone in the presence of rivals (Zizzari et al., 2013).

Importantly, sex pheromones and their detection can be affected by many external biotic and abiotic factors (e.g., presence of plant volatile compounds, density, temperature, wind, humidity, pollution). In the following, we explore a range of species in which temperature shifts have been shown to hamper their sexual chemical signalling and we highlight the importance of elucidating the consequences of the loss of efficacy of sex pheromone communication.

\section{The role of temperature in sexual chemical communication}

Only a handful of studies has investigated the sensitivity of sexual chemical signalling to changes in temperature, while organisms experience increasing temperature variations in their natural environment due to climate change. Importantly, thermal stress can affect pheromone communication at different stages of the pheromone journey, from biosynthesis to detection (fig. 1).

\section{Biosynthesis}

Thermal stress is expected to affect the enzymatic activity underlying the synthesis of pheromones (Boullis et al., 2016). For example, in the springtail $O$. cincta, the spermatophore-associated sex pheromone plays a crucial role in female choice (Zizzari et al., 2013, 2017). Males exposed to heat stress $\left(35.2^{\circ} \mathrm{C}\right)$ produced spermatophores that were less attractive to females than spermatophores produced by

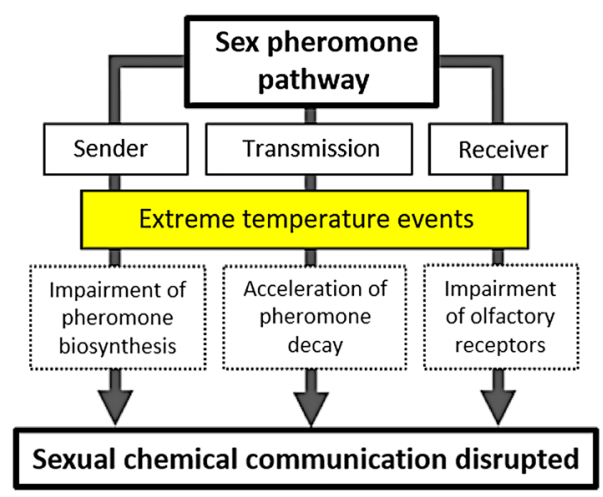

Figure 1. A general schematic showing the three phases of the pheromone journey and the possible effects of extreme temperature events on sexual chemical communication through each phase of the pheromone pathway. 
control males (Zizzari et al., 2011), suggesting that in this species male exposure to heat affects the spermatophore pheromone biosynthetic pathway, altering its composition. In the potato tuberworm moth Phthorimaea operculella (Zeller, 1873) (Ono, 1994), females exposed to high temperature $\left(35^{\circ} \mathrm{C}\right)$ modified the ratio of their sex pheromone components, which was most evident in the pupal stage (Ono, 1993, 1994). In another moth species, Helicoverpa zea (Boddie, 1850), females exposed to warm temperature $\left(35^{\circ} \mathrm{C}\right)$ decreased the amount of the major component of the sex pheromone (Raina, 2003). Short-range and contact sex pheromones can also be affected by temperature variations. CHCs not only protect insects from dehydration, but also play an important role in mate recognition (e.g., Snellings et al., 2018). In three Drosophila species, courtship and mating were dramatically altered by heat stress (Patton \& Krebs, 2001); the observed behaviours were suggested to be a consequence of changes in the CHC composition that make males less attractive to females (Markow \& Toolson, 1990). Savarit \& Ferveur (2002) tested the effect of temperature on the production of sex-specific CHCs in Drosophila melanogaster (Meigen, 1830) and found a sex-specific sensitivity to heat shock. Interestingly, in the beewolf Philanthus triangulum (Fabricius, 1775) low temperature during larval development was found to affect both the amount and composition of the sex pheromone of adult males (Roeser-Mueller, 2010). Thus, temperature dependence of pheromone synthesis should take into account not only heat stress events but all acute temperature changes, depending on the species habitat or geographical distribution.

\section{Persistence}

Sex pheromones may be altered after their emission, and signal persistence in the environment can significantly decrease under warmer conditions, as a consequence of higher evaporation rate (McDonough et al., 1989). For instance, in the mountain lizard Iberolacerta cyreni (Müller \& Hellmich, 1937), detectability of male femoral secretions by females was found to be negatively affected by warm temperature $\left(22^{\circ} \mathrm{C}\right)$ due to decreased scent durability (Martín \& Lopez, 2013). In the red mason bee Osmia bicornis (Linnaeus, 1758), male and female sex-pheromone profiles changed significantly between two temperature regimes $\left(17\right.$ and $\left.22^{\circ} \mathrm{C}\right)(\mathrm{Conrad}$ et al., 2017).

Temperature increases can also interfere with sustainable strategies for pest control management. Research on the effect of temperature on the release of the synthetic sex pheromone of the gypsy moth, Lymantria dispar (Linnaeus, 1758) indicates that release of the pheromone in warmer climates could affect trap efficacy (Nation et al., 1993; Tobin et al., 2011).

\section{Detection}

Changes in temperature might modify not only the sender information, but also the way the receiver perceives information. In the animal kingdom there is a plethora of 
chemosensory receptors, which have the same organization in most animal species (Wyatt, 2017). Thus, given the lipid component of the membranes surrounding receptor proteins (Hanada et al., 1994), a correlation between temperature dependence of membrane fluidity and odour sensitivity is not surprising. Remarkably, the consequences of an extreme temperature increase on the perception of sex pheromone have not received adequate attention. One of the few studies addressing the consequences of thermal stress on sex pheromone detection found that the degree of response specificity of male Oriental fruit moths, Grapholita molesta (Busck, 1916) and pink bollworm moths, Pectinophora gossypiella (Saunders, 1844), to different pheromone titres was altered by higher temperatures (Linn et al., 1988).

\section{Linking chemical signalling and sexual interactions under climate warming}

As thermal stress can alter the sex pheromones and the responses to these signals, thus impacting both emitter and receiver, population fitness may be affected (Henneken \& Jones, 2017). There is evidence that pheromones employed in mate assessment reflect the genetic quality of the signaler (e.g., Chemnitz et al., 2015), so that the question becomes: what are the evolutionary consequences of decreased efficacy for pheromones under sexual selection? A subtle shift in the quantity or quality of the sex pheromone profile could disrupt mate recognition with negative effects on population viability. Temperature shifts may result not only in the receiver not obtaining the correct information about prospective mates (by a change in the pheromone profile), but they can also affect the way the pheromone is perceived (i.e., receptors are not able capture the odour). A better knowledge of the interplay between pheromones and environment may help elucidate which selective pressures act on emission of pheromone titre and receiver's olfactory organs.

A reduced odour perception might determine a weak sexual selection if the signalers invest less resources in pheromone production, or could lead to signalers reinforcing the odours. Sexual selection could also favour individuals with greater olfactory sensitivity, if thermal stress affects the pheromone quantity a signaler emits. For example, in the moth Uraba lugens Walker, 1863, Johnson et al. (2017a) found that the antennal length of males is related to their ability to detect female sex pheromones, likely due to longer antennae supporting a higher number of sensilla. Moreover, $U$. lugens males adjust their investment in antennae according to environmental cues (Johnson et al., 2017b). However, how the strength of sexual selection could be affected by an impaired neural pathway involved in the odour perception and/or shift in pheromone profile is difficult to predict. Finally, changes in signal transmission and detection might possibly lead to hybridization between closely related species with similar mating signals. 


\section{Conclusions and future prospects}

To determine whether animal chemical communication systems are able to adapt to the rapidly changing environment, and how and whether extreme weather events influence the olfactory sensory receptors, a connection between different disciplines is required, ranging from evolutionary physiology to chemical ecology. Comparative studies that measure the consequences of climate change for sex pheromones and overall reproductive fitness in species with different geographical distributions will give insight in how generalist and specialist species may differ in their vulnerability to environmental change. This information is not only important for understanding possible changes in biodiversity patterns, but also for taking nature conservation measures as well as developing sustainable pest management strategies. Many moth species are important agricultural pests and climate change is expected to impact on the abundance, distribution ranges and phenology of many Lepidoptera (Kocsis $\&$ Hufnagel, 2011). Information on the consequences of the loss of efficacy of sex pheromones will lead to a better understanding of the fate of synthetic pheromones used in insect management programs, thus ensuring the efficiency of the trapping systems and mating disruptions techniques. Knowing whether and which sexual chemical communication systems are able to adapt to rapid environmental changes is of paramount importance and should be a direction for future research.

\section{Acknowledgements}

We wish to thank the anonymous reviewers for insightful feedback. This work was supported by the University of Koblenz-Landau.

\section{References}

Ache, B.W. \& Young, J.M. (2005) Olfaction: diverse species, conserved principles. Neuron, 48, 417430.

Borne, F., Kasimatis, K.R. \& Phillips, P.C. (2017) Quantifying male and female pheromone-based mate choice in Caenorhabditis nematodes using a novel microfluidic technique. PLoS One, 12, e0189679. DOI:10.1371/journal.pone.0189679.

Boullis, A., Detrain, C., Francis, F. \& Verheggen, F.J. (2016) Will climate change affect insect pheromonal communication? Curr. Opin. Insect Sci., 17, 87-91.

Brennan, P.A. \& Zufall, F. (2006) Pheromonal communication in vertebrates. Nature, 444, 308-315.

Caro, S.P. \& Balthazart, J. (2010) Pheromones in birds: myth or reality? J. Comp. Physiol. A Neuroethol. Sens. Neural Behav. Physiol., 196, 751-766.

Caro, S.P., Balthazart, J. \& Bonadonna, F. (2015) The perfume of reproduction in birds: chemosignaling in avian social life. Horm. Behav., 68, 25-42.

Caspermeyer, J. (2016) Evolutionary study of birds' sense of smell reveals important clues for behavior and adaptation. Mol. Biol. Evol., 33, 295-296.

Chemnitz, J., Jentschke, P.C., Ayasse, M. \& Steiger, S. (2015) Beyond species recognition: somatic state affects long-distance sex pheromone communication. Proc. Biol. Sci., 282, 20150832. DOI:10.1098/rspb.2015.0832. 
Conrad, T., Stöcker, C. \& Ayasse, M. (2017) The effect of temperature on male mating signals and female choice in the red mason bee, Osmia bicornis (L.). Ecol. Evol., 7, 8966-8975.

Foster, S.P. \& Johnson, C.P. (2010) Feeding and hemolymph trehalose concentration influence sex pheromone production in virgin Heliothis virescens moths. J. Insect Physiol., 56, 1617-1623.

Gomez-Diaz, C. \& Benton, R. (2013) The joy of sex pheromones. EMBO Rep., 14, 874-883.

Groot, A.T., Blanco, C.A., Classen, A., Inglis, O., Santangelo, R.G., Lopez, J., Heckel, D.G. \& Schal, C. (2010) Variation in sexual communication of the tobacco budworm, Heliothis virescens. Southwest. Entomol., 35, 367-372.

Hanada, T., Kashiwayanagi, M. \& Kurihara, K. (1994) Temperature increase abolishes ability of turtle olfactory receptors to discriminate similar odorant. Am. J. Physiol., 266, R1816-R1823.

Hansen, A., Anderson, K.T. \& Finger, T.E. (2004) Differential distribution of olfactory receptor neurons in goldfish: structural and molecular correlates. J. Comp. Neurol., 477, 347-359.

Harari, A.R., Zahavi, T. \& Thiéry, D. (2011) Fitness cost of pheromone production in signaling female moths. Evolution, 65, 1572-1582.

Henneken, J. \& Jones, T.M. (2017) Pheromones-based sexual selection in a rapidly changing world. Curr. Opin. Insect Sci., 24, 84-88.

Johansson, B.G. \& Jones, T.M. (2007) The role of chemical communication in mate choice. Biol. Rev. Camb. Philos. Soc., 82, 265-289.

Johnson, T.L., Symonds, M.R.E. \& Elgar, M.A. (2017a) Sexual selection on receptor organ traits: younger females attract males with longer antennae. Sci. Nat., 104, 44. DOI:10.1007/s00114-0171466-4.

Johnson, T.L., Symonds, M.R.E. \& Elgar, M.A. (2017b) Anticipatory flexibility: larval population density in moths determines male investment in antennae, wings and testes. Proc. Biol. Sci., 284, 20172087. DOI:10.1098/rspb.2017.2087.

Kaissling, K.E. (2014) Pheromone reception in insects (the example of silk moths). In: C. MucignatCaretta (Ed.) Neurobiology of Chemical Communication, pp. 99-146. CRC Press, Boca Raton, FL, USA.

Keller-Costa, T., Hubbard, P.C., Paetz, C., Nakamura, Y., da Silva, J.P., Rato, A., Barata, E.N., Schneider, B. \& Canario, A.V.M. (2014) Identity of a tilapia pheromone released by dominant males that primes females for reproduction. Curr. Biol., 24, 2130-2135.

Kocsis, M. \& Hufnagel, L. (2011) Impacts of climate change on Lepidoptera species and communities. Appl. Ecol. Environ. Res., 9, 43-72.

Landolt, P.J. \& Phillips, T.W. (1997) Host plant influences on sex pheromone behavior of phytophagous insects. Annu. Rev. Entomol., 42, 371-391.

Linn, C.E., Campbell, M.G. \& Roelofs, W.L. (1988) Temperature modulation of behavioural thresholds controlling male moth sex pheromone response specificity. Physiol. Entomol., 13, 59-67.

Lürling, M. \& Scheffer, M. (2007) Info-disruption: pollution and the transfer of chemical information between organisms. Trends Ecol. Evol., 22(7), 374-379.

Markow, T.A. \& Toolson, E.C. (1990) Temperature effects on epicuticular hydrocarbons and sexual isolation in Drosophila mojavensis. In: J.S.F. Barker, W.T. Starmer \& R.J. MacIntyre (Eds) Ecological and Evolutionary Genetics of Drosophila, pp. 315-331. Plenum, New York, NY, USA.

Martín, J. \& López, P. (2010) Condition-dependent pheromone signaling by male rock izards: more oily scents are more attractive. Chem. Senses, 35, 253-262.

Martín, J. \& López, P. (2013) Effects of global warming on sensory ecology of rock lizards: increased temperatures alter the efficacy of sexual chemical signals. Funct. Ecol., 27, 1332-1340. 
Martín, J. \& López, P. (2014) Pheromones and chemical communication in lizards. In: J.L. Rheubert, D.S. Siegel \& S.E. Trauth (Eds) Reproductive Biology and Phylogeny of Lizards and Tuatara, pp. 43-75. CRC Press, Boca Raton, FL, USA.

Martín, J., Moreira, P.L. \& López, P. (2007) Status-signalling chemical badges in male Iberian rock lizards. Funct. Ecol., 21, 568-576.

McDonough, L.M., Brown, D.F. \& Aller, W.C. (1989) Insect sex pheromones: effect of temperature on evaporation rates of acetates from rubber septa. J. Chem. Ecol., 15, 779-790.

Nakada, T., Toyoda, F., Matsuda, K., Nakakura, T., Hasunuma, I., Yamamoto, K., Onoue, S., Yokosuka, M. \& Kikuyama, S. (2017) Imorin: a sexual attractiveness pheromone in female red-bellied newts (Cynops pyrrhogaster). Sci. Rep., 7, 41334. DOI:10.1038/srep41334.

Nation, J.L., Foltz, J.L., Dixon, W.N. \& McAuslane, H.J. (1993) Evaluation of loss of (+)-disparlure from gypsy moth (Lepidoptera: Lymantriidae) pheromone dispenser dispenser tapes under field conditions in Florida. Fla. Entomol., 76, 584-589.

Novotny, M.V. (2003) Pheromones, binding proteins and receptor responses in rodents. Biochem. Soc. Trans., 31, 117-122.

Ono, T. (1993) Effect of rearing temperature on pheromone component ratio in potato tuberworm moth, Phthorimaea operculella, (Lepidoptera: Gelechiidae). J. Chem. Ecol., 19, 71-81.

Ono, T. (1994) Effect of temperature on biosynthesis of sex pheromone components in potato tuberworm moth, Phthorimaea operculella (Lepidoptera: Gelechiidae). J. Chem. Ecol., 20, 2733-2741.

Patton, Z.J. \& Krebs, R.A. (2001) The effect of thermal stress on the mating behaviour of three Drosophila species. Physiol. Biochem. Zool., 74(6), 783-788.

Porteus, C.S., Hubbard, P.C., Uren Webster, T.M., van Aerle, R., Canário, A.V.M., Santos, E.M. \& Wilson, R.W. (2018) Near-future $\mathrm{CO}_{2}$ levels impair the olfactory system of a marine fish. Nat. Clim. Change, 8(8), 737-743.

Raina, A.K. (2003) Pheromone production in corn earworm: effect of temperature and humidity. Southwest. Entomol., 28, 115-120.

Roeser-Mueller, K., Strohm, E. \& Kaltenpoth, M. (2010) Larval rearing temperature influences amount and composition of the marking pheromone of the male beewolf, Philanthus triangulum. J. Insect Sci., 10, 74. DOI:10.1673/031.010.7401.

Rosenthal, G.G. \& Stuart-Fox, D. (2012) Environmental disturbance and animal communication. In: U. Candolin \& B.B.M. Wong (Eds) Behavioural Responses to a Changing World: Mechanisms and Consequences, pp. 16-31. Oxford University Press, Oxford, UK.

Ruther, J., Matschke, M., Garbe, L.-A. \& Steiner, S. (2009) Quantity matters: male sex pheromone signals mate quality in the parasitic wasp Nasonia vitripennis. Proc. Biol. Sci., 276, 3303-3310.

Savarit, F. \& Ferveur, J.-F. (2002) Temperature affects the ontogeny of sexually dimorphic cuticular hydrocarbons in Drosophila melanogaster. J. Exp. Biol., 205, 3241-3249.

Snellings, Y., Herrera, B., Wildemann, B., Beelen, M., Zwarts, L., Wenseleers, T. \& Callaerts, P. (2018) The role of cuticular hydrocarbons in mate recognition in Drosophila suzukii. Sci. Rep., 8, 4996. DOI:10.1038/s41598-018-23189-6.

South, S.H., House, C.M., Moore, A.J., Simpson, S.J. \& Hunt, J. (2011) Male cockroaches prefer a high carbohydrate diet that makes them more attractive to females: implications for the study of condition dependence. Evolution, 65, 1594-1606.

Steiger, S. \& Stökl, J. (2014) The role of sexual selection in the evolution of chemical signals in insects. Insects, 5, 423-438.

Steiger, S., Meier, T. \& Müller, J.K. (2012) Fitness costs associated with chemical signaling. Commun. Integr. Biol., 5, 57-60. 
Thomas, M.L. (2011) Detection of female mating status using chemical signals and cues. Biol. Rev. Camb. Philos. Soc., 86, 1-13.

Tobin, P.C., Zhang, A., Onufrieva, K. \& Leonard, D.S. (2011) Field evaluation of effect of temperature on release of disparlure from a pheromone-baited trapping system used to monitor gypsy moth (Lepidoptera: Lymantriidae). J. Econ. Entomol., 104, 1265-1271.

van Oudenhove, L., Billoir, E., Boulay, R., Bernstein, C. \& Cerdá, X. (2011) Temperature limits trail following behaviour through pheromone decay in ants. Naturwissenschaften, 98, 1009-1017.

Vogt, R.G. (2005) Molecular basis of pheromone detection in insects. In: L.I. Gilbert, K. Iatro \& S. Gill (Eds) Comprehensive Insect Physiology, Biochemistry, Pharmacology and Molecular Biology, vol. 3. Endocrinology, pp. 753-804. Elsevier, London, UK.

Woodley, S.K. (2010) Pheromonal communication in amphibians. J. Comp. Physiol. A Neuroethol. Sens. Neural Behav. Physiol., 196, 713-727.

Wyatt, T.D. (2014) Pheromones and Animal Behavior: Chemical Signals and Signatures. 2nd Edition. Cambridge University Press, Cambridge, UK.

Wyatt, T.D. (2017) Pheromones. Curr. Biol., 27, R739-R743.

Zizzari, Z.V. \& Ellers, J. (2011) Effects of exposure to short-term heat stress on male reproductive fitness in a soil arthropod. J. Insect Physiol., 57, 421-426.

Zizzari, Z.V., van Straalen, N.M. \& Ellers, J. (2013) Male-male competition leads to less abundant but more attractive sperm. Biol. Lett., 9, 20130762. DOI:10.1098/rsbl.2013.0762.

Zizzari, Z.V., Engl, T., Lorenz, S., van Straalen, N.M., Ellers, J. \& Groot, A.T. (2017) Love at first sniff: a spermatophore-associated pheromone mediates partner attraction in a collembolan species. Anim. Behav., 124, 221-227. 